\title{
EFFECT OF FEEDING WITH HERB OF ERYTHRINA VARIEGATA TO BIOCOMPATIBILITY OF THE COCOON FIBER OF WILD SILK MOTH ATTACUS ATLAS FOR FUTURE APPLICATION AS BIOCOMPATIBLE OF SILK SUTURES
}

\section{TJOKORDA SARI NINDHIA ${ }^{1}$, TJOKORDA GDE TIRTA NINDHIA ${ }^{2 *}$, I WAYAN SURATA², ZDENEK KNEJZLIK ${ }^{3}$, TOMAS RUML ${ }^{3}$}

${ }^{1}$ Faculty of Veterinary Medicine Udayana University, Denpasar, Bali, Indonesia. ${ }^{2}$ Department of Mechanical Engineering, Faculty of Engineering, Udayana University, Jimbaran, Bali, Indonesia. ${ }^{3}$ Department of Biochemistry and Microbiology, Faculty of Food and Biochemical Technology, Prague, Czech Republic. Email: nindhia@yahoo.com/tirta.nindhia@me.unud.ac.id

Received: 25 March 2018, Revised and Accepted: 28 August 2018

\section{ABSTRACT}

Objectives: Silk is biocompatible as biomaterial and has been used commercially as sutures. More interesting properties of the silk are that the mechanical properties exceed all natural polymer and synthetic materials. In this research, a type of silk suture is being developed from species of Attacus atlas to obtain better biocompatible sutures. A. atlas is a species of silk moth that consume not only single types of leaves. The Quality of cocoon fiber then can be arranged base on the types of the leaves that is consumed. Better biocompatibility sutures comparing with recent commercial silk sutures which is not biocompatible, can be achieved by feeding with variety types of leaves. Silk suture that already established in the market is a base product of Bombyx mori species of silk which is only consume one type of leaf (mulberry leaves).

Methods: In this research, the A. atlas cocoon was produced by feeding with herb Erythrina variegate. The microstructure was observed, element composition as well as biocompatibles properties was investigated.

Results: A high composition of kalium $(\mathrm{K})$ as well as chloride $(\mathrm{Cl})$ is identified in the fiber. The released fiber from cocoon also indicates high biocompatibility that is promising as biocompatible suture.

Conclusion: The biocompatible fiber for future application as sutures is possible to be prepared by feeding the wild silkworm of $A$. atlas with leaf of E. variegate. The fiber is found rich with kalium (K) as well as chloride (Cl) with irregular shape of crystal at the surface of the fiber.

Keywords: Silk, herb, Erythrina variegate, Sutures, Biocompatibility.

(C) 2018 The Authors. Published by Innovare Academic Sciences Pvt Ltd. This is an open access article under the CC BY license (http://creativecommons. org/licenses/by/4. 0/) DOI: http://dx.doi.org/10.22159/ajpcr.2018.v11s3.30019

\section{INTRODUCTION}

Recently, silk has been developed as engineering fiber to make artificial composite for biomaterial in medical application. Silks that are obtained from the cocoon are become long-standing interest by the scientist. The cocoon biophysics structure should be understood to make it constructive and effective. The scientist recently put attention on appearance and behavior of cocoon produced by different type of silkworm [1].

Silks are protein that is spun into fibers by larvae of lepidoptera such as silkworms, mites, scorpions, flies, and spiders. Silks are produced through biosynthesis process in epithelial cells. The proteins are stored into the lumen of these glands prior spinning into fibers. It exhibits mechanical properties to their specific functions and has a different composition of amino [2].

The silk moth Attacus atlas (Fig. 1) is an insect species that can produce silk. Not like domesticated mulberry silkworm of Bombyx mori that eat only one type of plant (mulberry plant) or monophagous, the larvae or A. atlas feed variety of plants (oligophagous). They often move from one plant to another in their development. The maximum wingspan of this moth reaches $300 \mathrm{~mm}$. This is the largest wing of all moths. This species is found in Southeast Asia in tropical rainforest habitats at altitudes around $1500 \mathrm{~m} \mathrm{[3].}$

Tissues such as ligament, tendons, and bone are incapable of self-repair because of the diseased or damaged. It is required a substitute biomaterial to aid the healing process. Silk is slow degradability and biocompatible with impressive mechanical properties that render silk as a biomaterial for further exploration. Silk fibroin protein is mechanically robust and biocompatible so it can be designed to desired specifications [4].

The larvae of silk moth spin the silk threads to form cocoons. The function of the cocoon is to enwrap for metamorphosis. The variations in climate and diet resulted diversity in the properties and types of the cocoons and fibers produced by silk within the same species. The cocoons are composed of two proteins, namely fibroin and sericin. The function of these protein structures includes protection from predators, pathogens, parasitoids, and assisting to complete metamorphosis by moisture and thermal. The larvae of $A$. atlas produce cuticular wax from abdominal tubercles. This wax forms a dense, white, powder coating over dorsal and lateral surfaces of the larva. The function of waxes is for conservation of the water, anti-parasitoid, and anti-predator [5].

Medicinal plants provide molecules that lead to the discovery of new drugs. Plants derived biologically active compounds have become important source of drug. Because of the recognition of herbal medicine as an alternative of health care, plants derived biologically active compounds have become important source of drug. Erythrina variegate plants contain phytopharmaceuticals, which have very important applications in the fields of medicine for the prevention of diseases. Plant of Erythrina variegate are phenolic, exhibit antiallergenic, antimicrobial, antiatherogenic, antithrombotic, anti-inflammatory, cardioprotective, and vasodilatory effects [6]. 


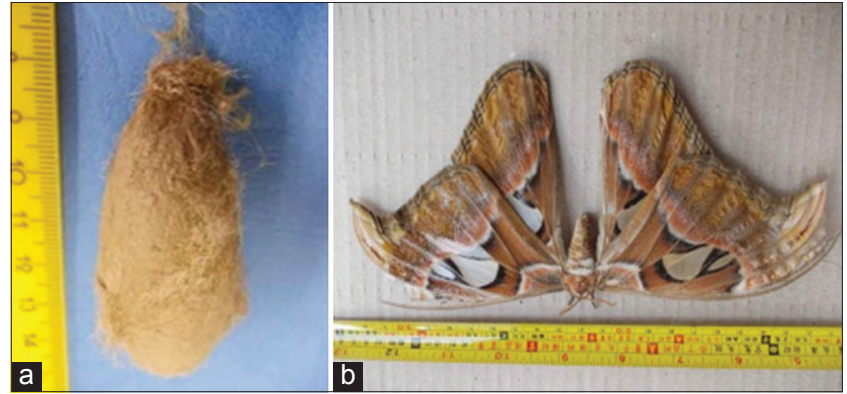

Fig. 1: Indonesia origin of cocoon (a) and silk moth of wild Attacus atlas (b)

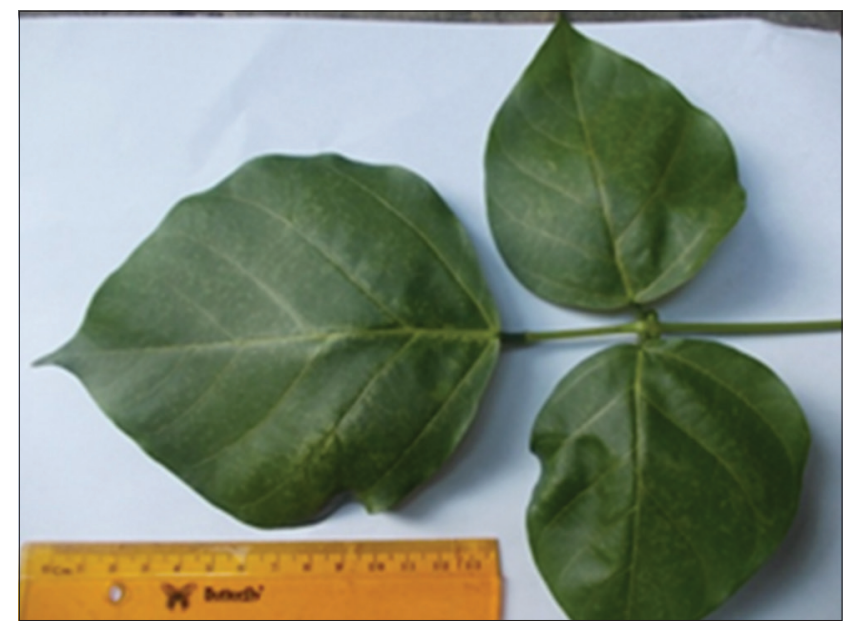

Fig. 2: Indonesian source leaf of Erythrina variegate



Fig. 3: Caterpillar of Attacus atlas consuming leaf of Erythrina variegate

E. variegate has been used in folk medicine for the treatment of an antihelminthic and narcotic, venereal disease, toothache, asthma, insomnia, and malarial fever. Alkaloids from E. variegate were investigated for their anticancer activity, a muscle relaxant, as well as hemoerythrin [7].

The bark of E. variegate traditionally is used to treat stomachache and swellings. Its leaves are occasionally used to treat wind-damp obstruction syndrome in rheumatic joint pain and spasm of the limbs or lower back and knee pain, to stimulate lactation and menstruation for women and eye ailments. Isoflavones are compounds in plant foods,

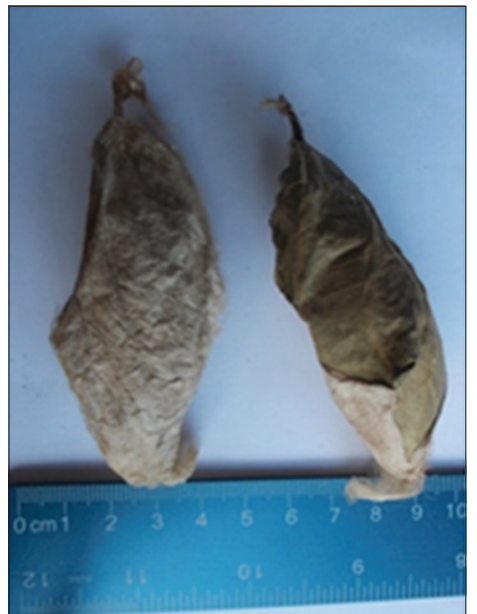

Fig. 4: Cocoon of Attacus atlas yield from feeding with Erythrina variegate

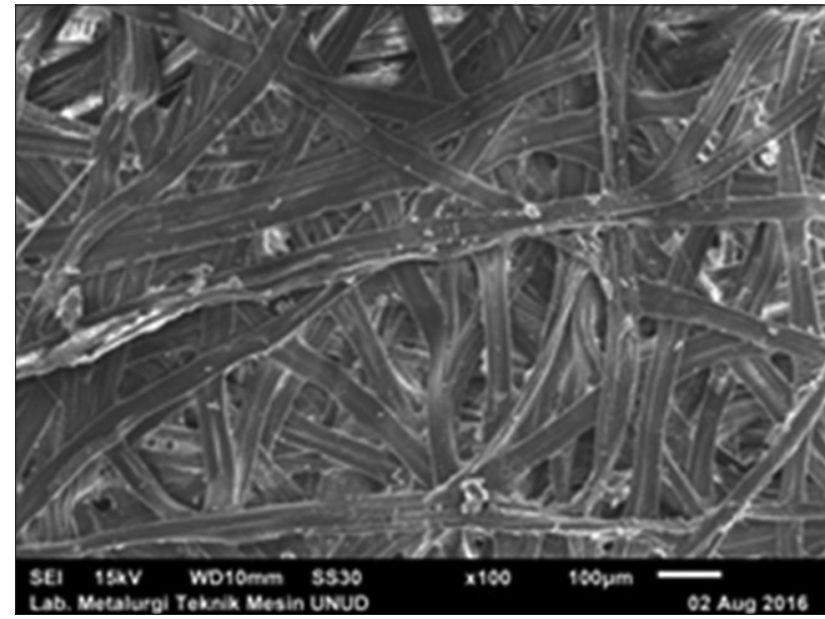

Fig. 5: Cocoon of Attacus atlas yield from feeding with Erythrina variegate $(\times 100)$

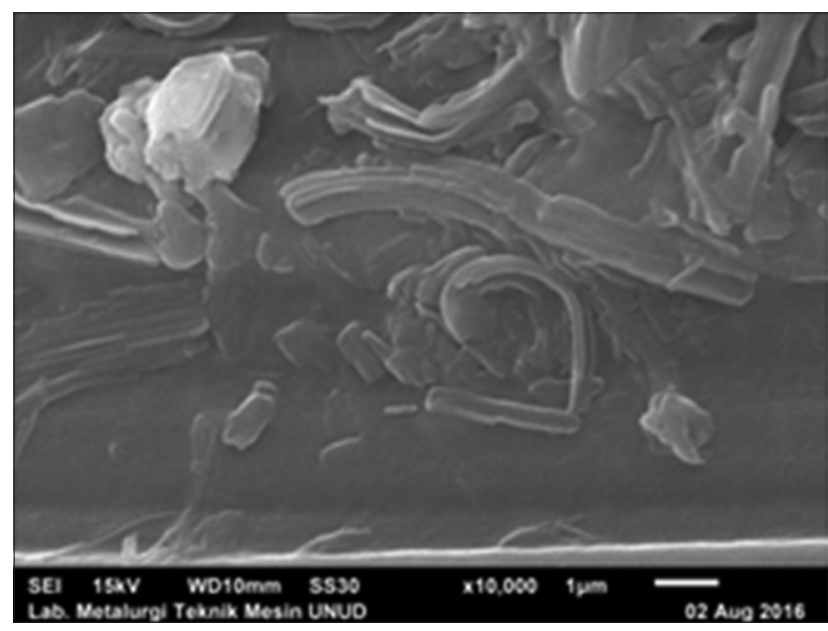

Fig. 6: Irregular crystal shape was found on the surface of the cocoon feeding with Erythrina variegate $(\times 10,000)$

structurally similar to the mammalian estrogens recently received attention for use in the prevention of postmenopausal bone loss. Data from animal experiments provided evidence that isoflavones can attenuate menopausal bone loss, and it was suggested that isoflavones 


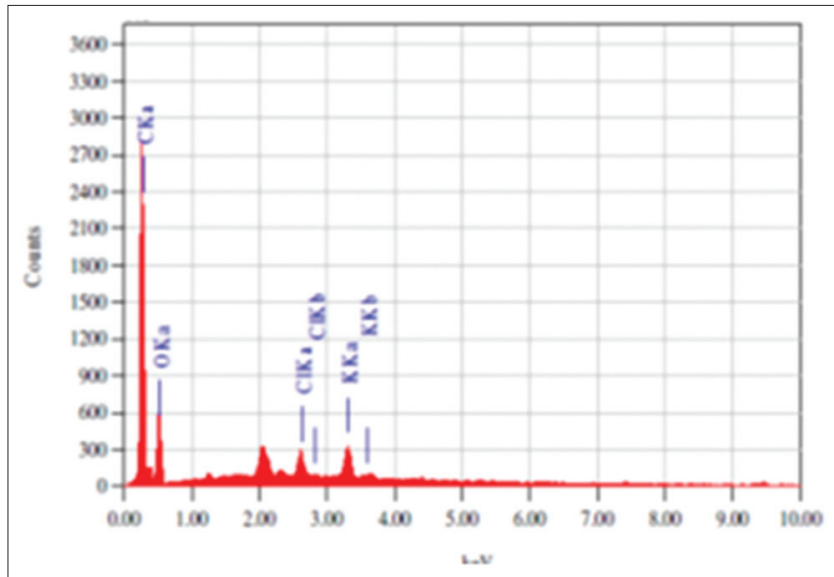

Fig. 7: Energy dispersive X-ray spectroscopy result on the cocoon feeding with Erythrina variegate
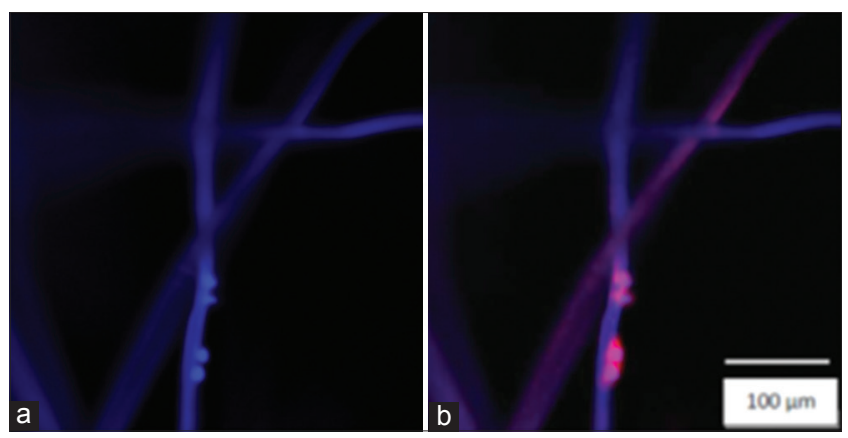

Fig. 8: (a and b) Cell growth on Attacus atlas fibers. U2OS cells were allowed to attach to the fibers and cultivated for 2 days. Nuclei were stained (using DAPI) and were analyzed by fluorescence and light microscopy

Table 1: Elements composition in the cocoon feeding with E. variegate

\begin{tabular}{llc}
\hline No & Element & Mass (\%) \\
\hline 1 & $\mathrm{C}$ & 64.86 \\
2 & $\mathrm{O}$ & 26.27 \\
3 & $\mathrm{Cl}$ & 2.96 \\
4 & $\mathrm{~K}$ & 5.92 \\
\hline
\end{tabular}

E. variegate: Erythrina variegate

are responsible for protective effects on bone. Phytochemical studies on E. variegate plant have led to the isolation of many isoflavones [8].

Phytochemical investigation of the non-alkaloidal secondary metabolites in Erythrina variegata revealed the presence of several isoflavonoids and one cinnamylphenol and which exhibit activities of antibacterial and anti-inflammatory. E. variegata is used medicinally as an antibacterial, antipyretic, anti-inflammatory, antiseptic agent, and as a collyrium. E. variegata is found in many tropical and subtropical regions [9].

E. variegate having positive result as antifungal again Aspergillus fumigates, Rhizoctonia solani, and Pythium ultimum but negative for Phytophthora parasitica. It is also found that $E$. variegate having negative result as antibacterial for Staphylococcus aureus and Escherichia coli [10].

In this research, the leaves from E. variegate are managed to become a food for A. atlas larvae. The cocoon obtained will be observed and the element contains in it will be identified as well as its biocompatibility to mammalian cells for future application as sutures.

\section{EXPERIMENTAL}

The egg of A. atlas was collected from their original location in Indonesia. The leaf of $E$. variegate (Fig. 2) was prepared from the source in Indonesia. Fig. 3 shows the appearance of caterpillars of A. atlas during consume leaf of $E$. variegate.

The special cage with the tree of $E$. variegate that was grown inside the cage was prepared. The caterpillars of $A$. atlas were let to consume the leaves E. variegate until reach their final stage inside the cage. At the final stage, the silkworm provides themselves cocoon for final step of metamorphose.

The silk moth of $A$. atlas was let free exit from the cocoon for the next breeding. The cocoons left by the silk moth were dried. The microstructure of the cocoon was investigated and recorded under scanning electron microscope (SEM). The energy dispersive X-ray spectroscopy method was introduced to reveal elements compositions in the cocoon. The result was presented in table and graphic.

For biocompatibility test, the cocoon of $A$. atlas was boiled in $0.1 \mathrm{M}$ $\mathrm{NaOH}$ for about $1 \mathrm{~h}$. Released fibers obtained were washed by hot water. Released fibrous tufts were sterilized with ethanol for 1 day at room temperature. Samples were washed by PBS. Fibrous tuft was soaked with suspension of U2OS cells in DMEM cultivation medium supplemented with $10 \%$ FBS ( 105 cells per $\mathrm{ml}$ ) for $2 \mathrm{~h}$ in the atmosphere of $5 \% \mathrm{CO}_{2}$. The humidity was $95 \%$ and temperature at $37^{\circ} \mathrm{C}$. The cell suspension was gently aspirated, and the fibers were immersed in the cultivation medium and the cells were cultivated for 2 days. The fibers were transferred to PBS and gently washed with PBS. Cells attached to the fibers were fixed with formaldehyde in PBS and washed. Nuclei were stained using DAPI Sigma-Aldrich (USA) and actin microfilaments by phalloidin covalently conjugated with TRITC (Sigma-Aldrich, USA) in PBS. Fluorescence microscopy was carried by microscope IX-71 (Olympus, Japan).

\section{RESULTS AND DISCUSSION}

Fig. 4 shows the appearance of the cocoon that is obtained by feeding with leaf E. variegate.

Result on observation using SEM with low magnification $(\times 100)$ can be shown in Fig. 5. Irregular crystals were found on the surface of the cocoon that was feeding with $E$. variegate at very high magnification $(\times 10,000)$ as can be shown in Fig. 6 .

Elements analysis with energy dispersive X-ray spectroscopy on the surface of the cocoon reveals that by feeding the larvae of $A$. atlas with E. variegate resulting the cocoon contains chlorine $(\mathrm{Cl})$ around 2.96 mass percentage (Fig. 7). The other elements were found carbon (C), oxygen (0), and kalium ( $\mathrm{K}$ ) as can be shown in Table 1. Other species of wild silk cocoon usually have cubic crystal on the surface such as Antheraea pernyi, Hyalophora gloveri, and Bunaea aleinoc [1].

Finally, we analyzed biocompatibility of the fibers obtained by degumming of $A$. atlas using $0.1 \mathrm{M} \mathrm{NaOH}$. The fibers were sterilized by ethanol and a suspension of human osteosarcoma cell line (U2OS) was applied. The cells were able to attach and grow during following 2 days, indicating their excellent biocompatibility. The cells were attached and grew well on the fiber surface(Fig. 8).

\section{CONCLUSION}

The biocompatible fiber for future application as sutures is possible to be prepared by feeding the wild silkworm of A. atlas with leaf of E. variegate. The fiber is found rich with kalium $(\mathrm{K})$ as well as chloride (Cl) with irregular shape of crystal at the surface of the fiber.

\section{ACKNOWLEDGMENT}

The authors wish to acknowledge financial support from grants research (PDUPT) from Indonesian Minister of Research Technology and Higher Education through Udayana University Bali, Indonesia 
(No. 171.76/UN14.4.A/LT/2018). Support from the Institute Chemical Technology Prague, Czech Republic, is very much acknowledged.

\section{REFERENCES}

1. Chen F, Porter DF, Vollrath F. Morphology and structure of silkworm cocoons. Mater Sci Eng C 2012;32:772-8.

2. Altman GH, Diaz F, Jakuba C, Calabro T, Horan RL, Chen J, et al. Silkbased biomaterials. Biomaterials 2003;24:401-16

3. Chen MM, Li Y, Chen M, Wang H, Li Q, Xia RX, et al. Complete mitochondrial genome of the atlas moth, Attacus atlas (Lepidoptera: Saturniidae) and the phylogenetic relationship of Saturniidae species. Gene 2014;545:95-101.

4. Nindhia TG, Koyoshi Y, Kaneko A, Sawada H, Ohta M, Hirai S, et al. Hydroxyapatite-silk functionally graded material by pulse electric current sintering. Trends Biomater Artif Organs 2008;22:28-33.

5. Jones CG, Young AM, Jones TH, Blum MS. Chemistry and possible roles of cuticular alcohols comp. Biochem Physiol 1982;73:797-801.

6. Muthukrishnan S, Palanisamy S, Subramanian S, Selvaraj S, Mari KR, Kuppulingam R. Phytochemical profile of Erythrina variegata by using high-performance liquid chromatography and gas chromatographymass spectroscopy analyses. J Acupunct Meridian Stud 2016;9:207-12.

7. Jyothirmayi T, Rao PG, Walde SG. Nitrogen extractability and functional properties of defatted Erythrina variegata flour. Food Chem 2006;96:242-7.

8. Zhang Y, Li X, Lai WP, Chenc B, Chow HK, Fu C, et al. Antiosteoporotic effect of Erythrina variegata in ovariectomized rats. J Ethnopharmacol 2007;109:165-9.

9. Tanaka H, Hirata M, Etoh H, Shimizu H, Sako M, Murata J, et al. Eryvarins F and G, 3-phenoxychromones from the roots of Erythrina variegate. Photochemistry 2003;62:1243-46.

10. Goun E, Cunningham G, Chu D, Nguyen C, Miles D. Antibacterial and antifungal activity of Indonesian ethnomedical plants. Fitoterapia 2003;76:592-96 